\title{
Editorial: Cutting-Edge Analogue Modeling Techniques Applied to Study Earth Systems
}

\author{
Christoph von Hagke ${ }^{1 *}$, Jacqueline Reber ${ }^{2}$ and Mélody Philippon ${ }^{3}$ \\ ${ }^{1}$ Institute of Geology and Paleontology, RWTH Aachen University, Aachen, Germany, ${ }^{2}$ Department of Geological and \\ Atmospheric Sciences, lowa State University, Ames, IA, United States, ${ }^{3}$ Université des Antilles, UMR 5243 Géosciences \\ Montpellier, Pointe-a-Pitre, France
}

Keywords: analog modeling, tectonics, structural geology, editorial, scaling and modeling

\section{Editorial on the Research Topic}

\section{Cutting-Edge Analogue Modeling Techniques Applied to Study Earth Systems}

\section{OPEN ACCESS}

Edited and reviewed by: Valerio Acocella

Roma Tre University, Italy

${ }^{\star}$ Correspondence: Christoph von Hagke christoph.vonhagke@ emr.rwth-aachen.de

Specialty section:

This article was submitted to Structural Geology and Tectonics,

a section of the journal

Frontiers in Earth Science

Received: 05 July 2019

Accepted: 25 September 2019

Published: 16 October 2019

Citation:

von Hagke C, Reber J and

Philippon M (2019) Editorial: Cutting-Edge Analogue Modeling

Techniques Applied to Study Earth Systems. Front. Earth Sci. 7:265. doi: 10.3389/feart.2019.00265
Our understanding of Earth systems is built on field observations, geological and geophysical investigations and modeling. For over two hundred years, geologists are building analog models to test theories and understand the physics leading to field observations. Analog models do not aim to reproduce nature but rather to simplify the system so that parameters like geometry, kinematics, or dynamics can be isolated and investigated. Analog models allow to investigate complex three-dimensional problems at high-resolution. In addition to deciphering outcrop observations, analog models offer the opportunity to predict structures not accessible for direct observation. Analog models provide a full $4-\mathrm{D}$ view of geological processes, allowing for investigating the time evolution of structures.

To develop new and successful analog experiments several challenges need to be overcome. Firstly, the governing physical processes in nature need to be identified and isolated and adequate modeling techniques need to be identified. This will govern the applied boundary conditions, model material, and it will determine the limitations of the experiment. Experiments then have to be benchmarked against field or geophysical observations to ensure their relevance. Secondly, new model materials with adequate physical properties need to be developed and tested to quantify their dependence on (i) strain and strain rate; (ii) temperature; (iii); and interaction with the boundaries or other materials. For example, the lithosphere was historically modeled as a two to four-layer brittle/ductile sandwich to crudely approximate the seismically observed rheology. However, the recent development of semi-brittle and temperature dependent model materials will change the way lithosphere and crustal-scale models are constructed. Thirdly, deformation apparatuses need to be developed emulating physical parameters such as erosion through rain, overpressure, or temperature gradients. Designing and tuning relevant Earth science experiments often involves genuine engineering and technical developments. And finally, the outcomes of the model need to be quantified with accurate tools such as particle image velocimetry (PIV), stress and strain sensors, strain maps, elevation maps (erosion rates, uplift rates).

This Research Topic compiles eight contributions either introducing and using new analog modeling techniques or using analog models to investigate geological observations in a new light.

\section{DEVELOPMENT OF NEW ANALOG MODELING TECHNIQUES}

Rudolf et al. present a technique to capture earthquake events in a sandbox without oversampling the interseismic period. Modeling earthquakes in a sandbox is challenging, as the speeds of plate motion and seismic slip vary by several orders of magnitude. Moreover, the recurrence 
intervals of earthquakes are impossible to forecast, even under controlled conditions of an experiment. The study introduces a new technique on how to monitor rate dependent processes in analog experiments.

Poppe et al. study intrusion of magma into host rock. Understanding intrusion geometries and monitoring their surface response helps forecasting volcanic eruptions. Results show that the strength of the host rock systematically affects the 3-D geometry and time- evolution of magma intrusions. Different endmember geometries can be distinguished. Intrusions into complex host rheology can result in filled mode-1-fractures and formation of mixed-mode fractures.

Svanes Bertelsen et al. investigate the mechanics of magma emplacement in Earth's crust. Experiments show strong correlation between intrusion shapes and host matrix deformation modes. These are the first experiments to produce the natural diversity of intrusion shapes and host deformation mechanisms. They also show that the use of a polariscope in gel experiments is essential to unravel the mechanics of emplacement within a rheologically complex host material.

To accurately monitor advection and uplift of material in analog models, horizontal and vertical displacements need to be measured. Toeneboehn et al.; Toeneboehn et al. present a costeffective solution requiring only two DSLR cameras and Matlab ${ }^{\circledR}$ toolboxes. The authors demonstrate how the combination of PIV, PTV, and stereovision analysis reveals the evolution of a fault system and three-dimensional advection of material in an experiment simulating the Mount McKinley restraining bend.

\section{NEW LOOK AT GEOLOGICAL PROBLEMS}

Beniest et al. conduct a series of lithosphere-scale analog models to investigate how strength variations of the margin influence margin geometries. Results show that rheologies control strain localization and geometries. Consistently, the weaker section of the experiment is stretched, and deformation does not localize at the rheological contrast between the two different crusts. The results show comparability to the passive margin geometries observed on both sides of the Atlantic.

Large transform faults have been suggested as one setting where subduction initiation could take place. Analog models by Boutelier and Beckett show that at constant convergence rate subduction initiation requires formation of new thrusts near the transform fault. Only at specific orientations of these weak zones will the older, less buoyant plate become the subducted plate. The model results can be applied to a variety of natural examples, including the New Hebrides or the Caribbean subduction zone. von Hagke et al. investigate the influence of obliquity of slip on the evolution and geometry of dilatant faults to quantitatively determine which surface structures are characteristic features to determine slip kinematics. They show that dilatancy changes progressively with increasing obliquity. Open fractures may occur at depth of $>1 \mathrm{~km}$. These findings have implications for our understanding of the connectivity of faults at depth, and geothermal systems.

Experiments by Brun and Fort show that continental shelves are sensitive to changes in the tectonic history, and therefore are important for understanding the time-evolution of passive margins. They show that transfer zones develop connecting two shelf breaks, and these transfer zones are markers for kinematic analyses. This study shows that complex systems such as passive margins are accessible using analog models.

The presented collection of papers provides insights into the state of the art in analog modeling. They demonstrate how new techniques are driving the field in an increasingly quantitative direction and illustrate the breadth of questions that can be addressed with analog modeling. Analog models will continue to play an essential role alongside field observations and theoretical considerations in driving our understanding of tectonic processes in new directions.

The figure accompanying this editorial can be found at: "https://figshare.com/articles/CvH_et_al_Analog_Modeling FES_jpg/8983862.”

\section{AUTHOR CONTRIBUTIONS}

All authors listed have made a substantial, direct and intellectual contribution to the work, and approved it for publication.

\section{ACKNOWLEDGMENTS}

We would like to thank all reviewers for their contributions to the manuscripts. We also would like to thank editors in Chief Valerio Acocella and Agust Gudmundsson and the Frontiers Team for their support.

Conflict of Interest: The authors declare that the research was conducted in the absence of any commercial or financial relationships that could be construed as a potential conflict of interest.

Copyright (c) 2019 von Hagke, Reber and Philippon. This is an open-access article distributed under the terms of the Creative Commons Attribution License (CC BY). The use, distribution or reproduction in other forums is permitted, provided the original author(s) and the copyright owner(s) are credited and that the original publication in this journal is cited, in accordance with accepted academic practice. No use, distribution or reproduction is permitted which does not comply with these terms. 